\title{
The effect of long-term administered CRAC channels blocker on the functions of respiratory epithelium in guinea pig allergic asthma model
}

\author{
Martina Sutovska ${ }^{1}$, Michaela Kocmalova ${ }^{1}$, Marta Joskova ${ }^{1}$, Marian Adamkov $^{2}$ \\ and Sona Franova ${ }^{1}$ \\ ${ }^{1}$ Department of Pharmacology, Jessenius Faculty of Medicine, Comenius University, Sklabinska Street 26, 03601 Martin, \\ Slovak Republic \\ ${ }^{2}$ Institute of Histology and Embryology, Jessenius Faculty of Medicine, Comenius University, Mala Hora 4, 03601 Martin, \\ Slovak Republic
}

\begin{abstract}
Previously, therapeutic potency of CRAC channels blocker was evidenced as a significant decrease in airway smooth muscle hyperreactivity, antitussive and anti-inflammatory effects. The major role of the respiratory epithelium in asthma pathogenesis was highlighted only recently and CRAC channels were proposed as the most significant route of $\mathrm{Ca}^{2+}$ entry into epithelial cells. The aim of the study was to analyse the impact of long-term administered CRAC channels blocker on airway epithelium, e.g. cytokine production and ciliary beat frequency (CBF) using an animal model of allergic asthma. Ovalbumin-induced allergic airway inflammation of guinea pigs was followed by long-term (14 days lasted) therapy by CRAC blocker (3-fluoropyridine-4-carboxylic acid, FPCA). The influence of long-term therapy on cytokines (IL-4, IL-5 and IL-13) in BALF and in plasma, immunohistochemical staining of pulmonary tissue (c-Fos positivity) and CBF in vitro were used for analysis. Decrease in cytokine levels and in c-Fos positivity confirmed an anti-inflammatory effect of long-term administered FPCA. Cytokine levels in BALF and distribution of c-Fos positivity suggested that FPCA was a more potent inhibitor of respiratory epithelium secretory functions than budesonide. FPCA and budesonide reduced CBF only insignificantly. All findings supported CRAC channels as promising target in the new strategy of antiasthmatic treatment.
\end{abstract}

Key words: CRAC channels - Cytokines - Ovalbumine - Airway hyperreactivity - c-Fos

\section{Introduction}

Calcium release-activated calcium (CRAC) channels are widely expressed in various tissues, but their properties and functions outside the immune system remain largely unexplained. Two proteins have been identified which play a major role in CRAC channels functions: pore-forming plasma membrane protein Orail and STIM1 acting as a sensor of $\mathrm{Ca}^{2+}$ concentration in the endoplasmic reticulum and activates $\mathrm{Ca}^{2+}$ entry from the extracellular

Correspondence to: Martina Sutovska, Department of Pharmacology, Jessenius Faculty of Medicine, Comenius University, Sklabinska 26, 03601 Martin, Slovak Republic

E-mail: sutovska@jfmed.uniba.sk space through Orail protein in response to a mobilisation of $\mathrm{Ca}^{2+}$ from intracellular sources (Parekh 2010; Sutovska et al. 2013b).

Within the immune system, $\mathrm{Ca}^{2+}$ entry through CRAC channels is a critical step in the functional responses of Tcells and mast cells in which they orchestrate mediator release, cytokine production and proliferation processes (Feske 2010). In asthmatic subjects, the sustained activation of CRAC channels located on Th2 (T helper 2) and mast cells plasma membrane is closely associated with activation of several transcription factors, e.g. NFAT (nuclear factor of activated T-cells), NF- $\mathrm{BB}$ (nuclear factor kappa-lightchain-enhancer of activated B cells) and AP-1 (activator protein 1), resulting in excessive production of IL-4, IL-5, IL-13 and TNF- $\alpha$ (Yoshino et al. 2007). 
The epithelial cells covering the airways comprise not only passive defence barrier against inhaled allergens, pathogens and irritants, but also play an active role in orchestrating inflammatory responses. They adjust both innate and adaptive immune reactions through the production of a wide array of secreted factors able to influence various cells of the immune system (Gwack at al. 2008; McNally et al. 2012). Epithelial cells produce cytokines via the $\mathrm{Ca}^{2+}$-responsive transcriptional regulators, NFAT (Davé et al. 2004) and NF- $\kappa B$ (Page et al. 2003). Fujioka et al. (2004) demonstrated distinct evidence of connection between NF- $\kappa$ B and AP-1 pathways and Macián et al. (2001) confirmed similar correlation between NFAT and AP-1. AP-1 is a transcription factor complex that is formed by dimerisation of members of the Fos and Jun proto-oncogene families. The increased levels of c-fos mRNA and c-Fos protein overexpression have been described in many in vitro and in vivo models of inflammation, including bronchial asthma (Adcock and Caramori 2001).

Although it is known that airway epithelial cells express these transcription factors, the source of $\mathrm{Ca}^{2+}$ entry that regulates them was proposed only recently by Prakryia (2009). Author demonstrated that CRAC channels serve as a major route of $\mathrm{Ca}^{2+}$ entry in lung epithelial cells leading to robust activation of NFAT and the production of proinflammatory cytokines in these cells.

The mucociliary clearance of respiratory epithelium represents a highly effective nonspecific immunological mechanism eliminating almost airway waste. This task is achieved due to the high degree of coordination between the individual cilia, and due to the ability of cilia to increase the ciliary beat frequency $(\mathrm{CBF})$ in response to various stimuli (Teff et al. 2008). The ciliary transport efficiency is linearly dependent on CBF. Elevation in intracellular $\mathrm{Ca}^{2+}$, situated near to plasma membrane, is one of the crucial triggers of CBF enhancement. Experimentally-induced depletion of intracellular $\mathrm{Ca}^{2+}$ stores results in activation of a continuous $\mathrm{Ca}^{2+}$ influx across the plasma membrane (Braiman and Priel 2001). According to Parekh and Putney (2005) empty intracellular stores are replenished probably via CRAC current. $\mathrm{Ca}^{2+}$ does not regulate $\mathrm{CBF}$ alone, but as a part of a complex, intimately interconnected, signalling network consisting of $\mathrm{Ca}^{2+}$, calmodulin and the cyclic nucleotide pathways (Zagoory et al. 2002).

Previously, our experimental studies evidenced significant involvement of CRAC channels in guinea pigs experimental allergic asthma model (Sutovska et al. 2013a, 2013b). These results showed dose-dependent decrease of airway hyperreactivity on single doses of CRAC channels blocker (3-fluoropyridine-4-carboxylic acid, FPCA) as well as decrease of basal airway reactivity and anti-inflammatory response on long-term FPCA administration. In this paper we report the effect of long-term administered CRAC chan- nels blocker on the functions of respiratory epithelium cells, e.g. cytokine production and mucociliary clearance, under the conditions of experimental allergic asthma.

\section{Materials and Methods}

All experiments were approved by the Institutional Ethics Committee of the Jessenius Faculty of Medicine, registered in Institutional Review Board/Institutional Ethic Board Office (IRB 00005636) in accordance with Slovakian and European Committee regulations for the use of laboratory animals and follow the criteria of experimental animal's welfare (decision No. 611/2010).

Adult male TRIK strain guinea pigs used in study, weighing 200-250 g, were obtained from accredited breeding facility situated in Department of Experimental Pharmacology, Slovak Academy of Sciences (Dobra Voda, Slovakia), and were housed in approved animal holding facility. Water and commercial feed were allowed ad libitum. The guinea pigs were free of respiratory airways infections as assessed by the regular health monitoring quality controls.

\section{Chemicals}

The chicken ovalbumine, aluminium hydroxide and budesonide were purchased from Sigma Aldrich (Lambda Life, Slovakia), 3-fluoropyridine-4-carboxylic acid from Alfa Aesar (Germany). Budesonide for nebulisation was prepared as suspension in $1 \%$ TWEEN 80 (in $0.9 \%$ saline) according to manufacturer's instruction, CRAC channels blocker was dissolved in water for injection and all other above-mentioned drugs in $0.9 \%$ saline.

\section{Design of the study}

The animals in total number 40 were used in experiments after one-week adapting period. Animals were divided into 4 groups; each consists of 10 animals, as follows:

1. Negative unsensitized control group (NC).

2. Negative sensitized control group $(\mathrm{OVA}+)$ - animals sensitized by ovalbumine received saline in the dose $1 \mathrm{ml} /$ $\mathrm{kg}$ b.w. intraperitoneally (i.p.) as long-term therapy.

3. Positive control group (BUD LT) - guinea pigs longterm received budesonide $(3 \mathrm{mg} / \mathrm{ml}$ by inhalation for $5 \mathrm{~min})$.

4. Experimental group (CRAC LT) - animals underwent long-term therapy by CRAC channels blocker 3-fluoropyridine-4-carboxylic acid in the dose $1.5 \mathrm{mg} / \mathrm{kg}$ b.w. i.p.

Experimental airways inflammation was induced by repetitive administration of ovalbumine adsorbed on aluminium hydroxide according to method previously 
described by Franova et al. (2013). Sensitization procedure was followed by saline, budesonide and 3-fluoropyridine4-carboxylic acid long-term (14 days lasted) treatment. All tests with sensitized and treated animals were accomplished 24 hour after last dose application.

\section{The assessment of cytokine levels}

The blood from guinea pigs heart was collected after transversal spinal cord interruption. To measure inflammatory mediators in the airways, bronchoalveolar lavage was performed after respiratory tract removal with volume of warm saline $\left(37^{\circ} \mathrm{C}\right)$ calculated according to body weight of animal $(10 \mathrm{ml} / \mathrm{kg})$. Saline was injected and withdrawal via the cannula placed into the right bronchus. Serum and supernatant from biological fluids were obtained by centrifugation - blood at the speed 3500 during $5 \mathrm{~min}$ and bronchoalveolar lavage fluid (BALF) at speed 1500 during 2 min.

The apparatus Bio-Plex ${ }^{\circledR} 200$ System and TH1/TH2 panel Human Cytokine (Bio-Rad, USA) were used for cytokine levels assessment. The capture sandwich immunoassay format was designed on magnetic beads according to a manufacturer's instructions. The capture antibody-coupled beads were first incubated with antigen standards, samples, or controls followed by incubation with biotinylated detection antibodies and reporter streptavidin-phycoerythrin (S-P) conjugate. Then beads were passed through the Bio-Plex 200 suspension array reader equipped with two lasers $(532 \mathrm{~nm}$ and $635 \mathrm{~nm}$ excitations), which measures the fluorescence of the beads and of the bound S-P.

High-speed digital processor manages data output and Bio-Plex Manager ${ }^{\mathrm{TM}} 6.0$ software presents results as concentration in $\mathrm{pg} / \mathrm{ml}$. All obtained data are shown as means \pm S.E.M. For their statistical analysis Student's t-test was used and the results with $p<0.05$ and lower were considered as statistically significant.

\section{Immunohistochemical analysis of c-Fos positivity}

Formalin-fixed and paraffin-embedded tissue samples of guinea pigs left lungs (size $10 \times 10 \times 5 \mathrm{~mm}$ ) were cut into $4 \mu \mathrm{m}$ sections which were dewaxed and rehydrated using xylene and alcohol. After preincubation with $0.1 \%$ hydrogen peroxide and protein blocking solution, the tissue sections were incubated with primary anti-c-Fos rabbit polyclonal antibody (Sigma-Aldrich, Slovakia) in dilution 1:50 overnight at $4^{\circ} \mathrm{C}$ in humidified chamber. Secondary biotinylated antirabbit antibody (Calbiochem, Merck Millipore, Germany) was applied for $30 \mathrm{~min}$ at room temperature. The sections were treated with $\mathrm{ABC}$ reagent for 30 min then were immersed in 1\% TRITON X-100 detergent in phosphate-buffered saline for $30 \mathrm{~s}$. Immunoreaction was visualized using 3, 3'diaminobenzidine chromogen solution. Negative controls were obtained by omitting the primary antibody. The nuclei were counterstained with Meyers' haematoxylin.

All double-blind labelled microscopic slides were evaluated by two independent observers (M.A., M.S.). Sections, where the discrepancy between observer's results was noticed, were repeatedly assessed by both observers together using dualhead microscope. In every processed specimen, the degree of c-Fos positivity and localization of these changes were analyzed. Degree of c-Fos positivity was semiquantitatively determined by grading system described previously by Sutovska et al. (2013b). We distinguished negative (degree 0 and 1 ) and positive (degree 2 and 3 ) results. We differentiated localization of c-Fos positive cells in airway epithelium (covering respiratory bronchioles and alveolar ducts) and in pulmonary parenchyma.

The Fisher's exact test was selected to evaluate the immunohistochemical features. The results with probability 0.05 and lower were considered as statistically significant.

\section{Evaluation of ciliary beat frequency $(C B F)$}

Experiments were carried out under the standard laboratory conditions (ambient temperature was maintained at $21-24^{\circ} \mathrm{C}$ and humidity at $55 \pm 10 \%$ using LG multi type air-conditioner, LG Neo plazma, Slovakia). The temperature of the microscopic glass slide and the saline (natrium chloratum $0.9 \%$ ) used as a nutritive medium for cilia, were kept in the range of $37-38^{\circ} \mathrm{C}$.

Following transversal interruption of the male guinea pigs neck spinal cord, transverse access to the trachea was made approximately in the middle of its normal length. Ciliated samples were obtained by cytology brush (diameter $2.5 \mathrm{~mm}$ ), which was dipped into the saline and then gently rotated on the mucosal surface of the animal trachea. Tracheal brushings were immediately placed into saline solution processed to microscopic preparation.

Microscopic preparations were examined 3 min after brushing the tracheal cilia by phase contrast inverted biological microscope (Kvant model IM1C, Slovakia) and beating ciliated cells were recorded using a digital high speed video camera (Basler A504kc; Basler AG, Germany) on frame rate from 256 to $512 \mathrm{fps}$ (frames per second). There were approximately 10-12 video records of the same microscopic preparation, each in duration 5-10 s, performed at $1 \mathrm{~min}$ intervals. Video records were analysed using LabVIEW ${ }^{\mathrm{TM}}$ software to generate a ciliary region of interest (ROI), intensity variation in selected ROI and intensity variance curve. Curve was then analyzed using fast Fourier transform (FFT) algorithm (Hargas et al. 2011). Fourier spectrum of each intensity variance curve is then equal to frequency spectrum of beating in selected ROI. 
The median of frequency $(\mathrm{Hz})$ for each ROI was selected for analysis, followed by calculation of their arithmetic means referred to definite $\mathrm{CBF}$ value for each microscopic preparation. CBF descriptive statistics were compared using Student's t-test or ANOVA, as appropriate. The data with $p<0.05$ and lower were evaluated as statistically significant.

\section{Results}

\section{Effect of long-term treatment on cytokine levels}

The long-term administration of CRAC channels blocker and budesonide significantly decreased levels of IL-4, IL-5, IL-13 and TNF- $\alpha$ in BALF in comparison with negative sensitized control group of guinea pigs (Fig. 1 and Fig. 2). Except for IL-5, the levels of cytokines in experimental group were almost similar to negative unsensitized control group, while these values of positive control group remained still significantly elevated. Furthermore, we followed significantly lower levels of IL-4 $(p<0.05)$ and IL-13 $(p<0.0001)$ in group treated long-term by CRAC channels blocker, when we compared effect of budesonide and FPCA.

Unlike assessment of cytokines in BALF, CRAC channels blocker significantly lowered IL-4, IL-13 and TNF- $\alpha$, while IL-5 levels were influenced only insignificantly in com- parison with negative sensitized control group. Budesonide distinctly inhibited production of all followed cytokines by circulating immune cells in serum and these decreases were significantly lower not only in comparison to negative sensitized control guinea pigs, but, except for IL-4, also to unsensitized animals (Fig. 1 and Fig. 2). FPCA compared to budesonide showed significantly higher effect only on TNF- $\alpha$ production and release $(p<0.01)$.

Immunohistochemical analysis of c-Fos positivity on longterm drugs administration

Semiquantitative analysis of all pulmonary tissue samples focused on c-Fos positivity confirmed a significant enhancement of this parameter in the negative sensitized control group (OVA + ) as well as significant reduction in tissue obtained from animals underwent long-term treatment by FPCA and budesonide (Table 1).

Except for degree of c-Fos positivity, our attention was directed on distribution of c-Fos positive cells. According to Table 1 it is distinct that airway epithelium c-Fos positivity was reduced with higher significance than the pulmonary parenchyma of the experimental group of animals, while budesonide, administered to positive control group, exhibited more significant suppression of c-Fos positivity in pulmonary parenchyma than in airway epithelium. Fig. 3 represents IHC finding of unsensitized animals (NC). Distinct c-Fos positivity of sensitized, vehicle-treated guinea
A

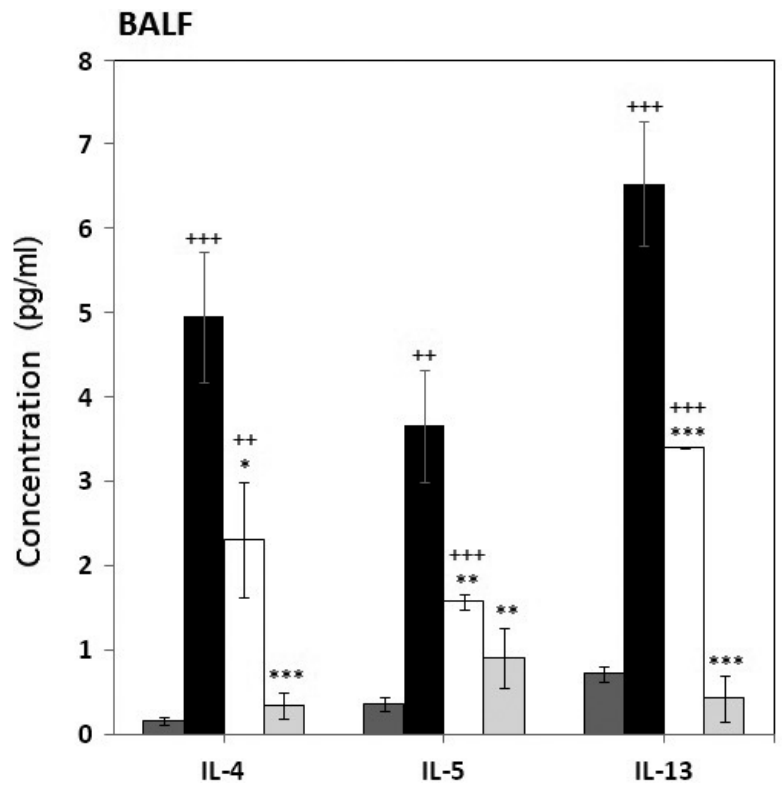

B

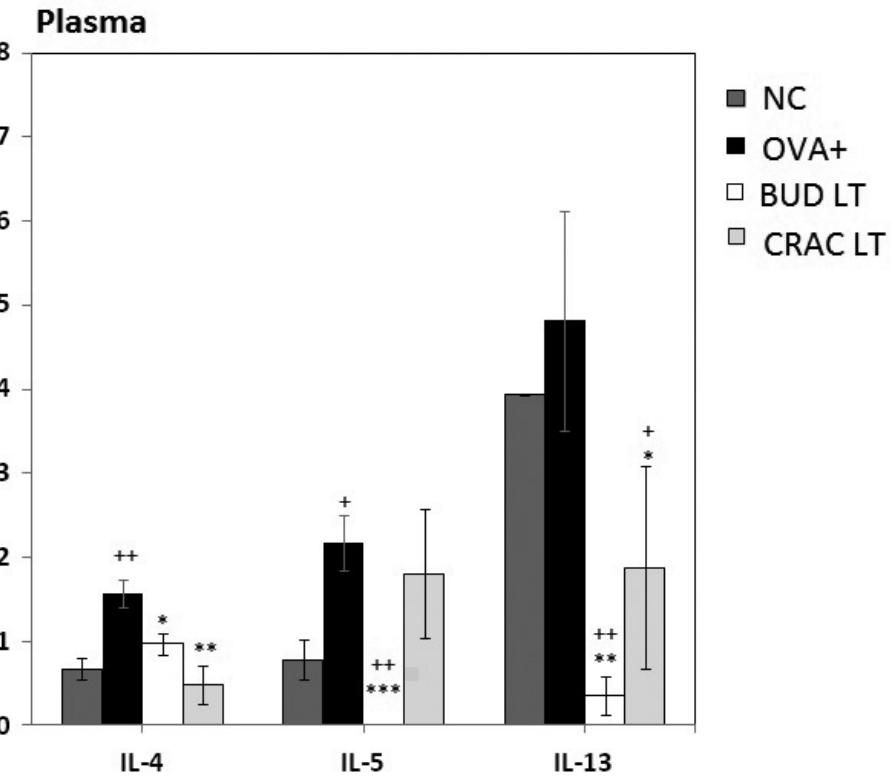

Figure 1. The changes in BALF (A) and plasma (B) levels of IL-4, IL-5 and IL-13 of unsensitized animals (NC), ovalbumine-sensitized guinea pigs (OVA+), animals treated long-term by FPCA (CRAC LT) and budesonide (BUD LT). The levels were evaluated 24 hours after administration of last drugs doses. ${ }^{*} p<0.05 ;{ }^{* *} p<0.01 ;{ }^{* * *} p<0.001 v s$. OVA $+;^{+} p<0.05 ;{ }^{++} p<0.01 ;^{+++} p<0.001 v s$. NC $(t$-test $)$. 

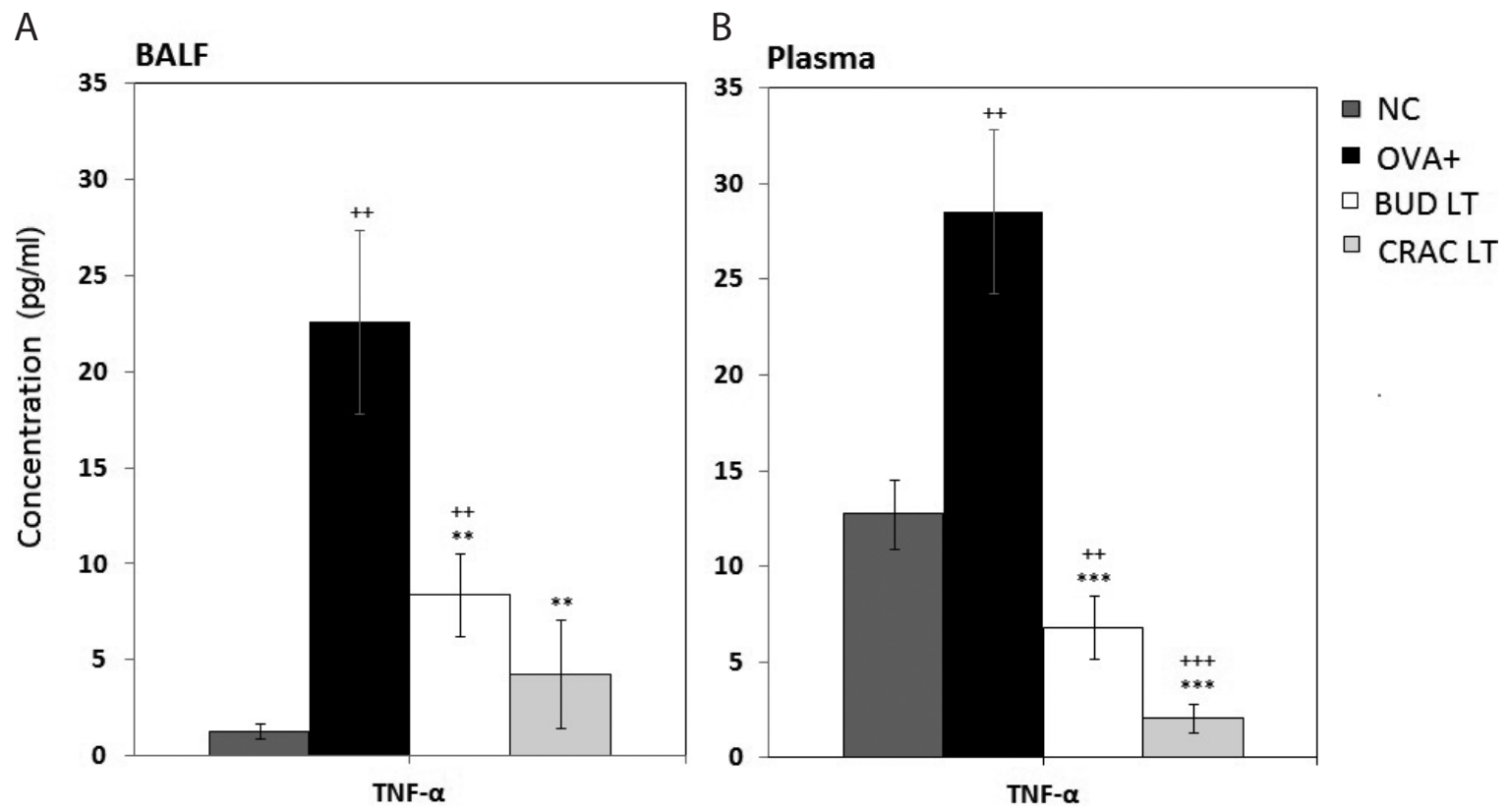

Figure 2. The changes in BALF (A) and plasma (B) levels of TNF- $\alpha$ measured in the same groups of animals. For explanation see Fig. 1.

pigs (OVA+) illustrates Figure 4. Figure 5 shows an example of positive (grade 2) infiltration by c-Fos positive cells (dark brown colour) in the pulmonary parenchyma seen in one sensitized animal treated long-term by FPCA and Figure 6 showed epithelial c-Fos positivity (grade 3 ) in an animal from the positive control group.

The influence of tested agents on ciliary beat frequency (CBF)

The CBF of ovalbumine-sensitized negative control group was significantly elevated in comparison with unsensitized control guinea pigs. CRAC channels blocker and budesonide influenced the assessed parameter only insignificantly, e.g. budesonide mildly enhanced and FPCA moderately decreased frequency of beating cilia (Fig. 7). It should be presumed that mucociliary clearance is not altered by experimental agent as well as positive control drug.

\section{Discussion}

Asthma is a chronic airway disease characterized by increased airway inflammation, mucus hypersecretion, airways remodelling, and increased bronchoconstrictor responses to provoking agonists (Lemanske and Busse 2010). Following allergen stimulation, several signal cascades are initiated during mast cells and T-cell activation and promote expression of several transcription factors, e.g. NFAT, AP-1 and NF- $\kappa \mathrm{B}$, respectively. These processes
Table 1. The results of c-Fos positivity assessment

\begin{tabular}{|c|c|c|c|c|c|c|c|c|}
\hline \multirow{2}{*}{$\begin{array}{l}\begin{array}{l}\text { Localization } \\
\text { of c-Fos positivity }\end{array} \\
\begin{array}{l}\text { Degree of c-Fos } \\
\text { positivity }\end{array}\end{array}$} & \multicolumn{4}{|c|}{ Epithelium } & \multicolumn{4}{|c|}{$\begin{array}{l}\text { Pulmonary } \\
\text { parenchyma }\end{array}$} \\
\hline & 0 & 1 & 2 & 3 & 0 & 1 & 2 & 3 \\
\hline NC & 7 & 1 & 0 & 0 & 5 & 3 & 0 & 0 \\
\hline number & \multicolumn{2}{|c|}{8} & \multicolumn{2}{|c|}{0} & \multicolumn{2}{|c|}{8} & \multicolumn{2}{|c|}{0} \\
\hline OVA+ & 0 & 1 & 2 & 4 & 0 & 1 & 3 & 3 \\
\hline number & \multicolumn{2}{|c|}{1} & \multicolumn{2}{|c|}{6} & \multicolumn{2}{|c|}{1} & \multicolumn{2}{|c|}{6} \\
\hline$p$ & \multicolumn{4}{|c|}{$0.0014^{\#}$} & \multicolumn{4}{|c|}{$0.00016^{\#}$} \\
\hline CRAC LT & 7 & 1 & 0 & 0 & 4 & 2 & 2 & 0 \\
\hline number & \multicolumn{2}{|r|}{8} & \multicolumn{2}{|c|}{0} & \multicolumn{4}{|c|}{2} \\
\hline$p$ & \multicolumn{4}{|c|}{$0.00016^{*}$} & \multicolumn{4}{|c|}{$0.0406^{*}$} \\
\hline BUD LT & 3 & 3 & 1 & 1 & 7 & 1 & 0 & 0 \\
\hline number & & 6 & & & & & & \\
\hline$p$ & \multicolumn{4}{|c|}{$0.0406^{\star}$} & \multicolumn{4}{|c|}{$0.0014^{*}$} \\
\hline
\end{tabular}

Immunohistochemical analysis of pulmonary sections focused on degree and localization of c-Fos positive cells infiltration. The number of negative (degree of c-Fos positivity 0 and 1 ) and positive (degree 2 and 3) samples was evaluated in unsensitized control group (NC), ovalbumin-sensitized animals (OVA+), experimental group of animals received long-term FPCA (CRAC LT) and positive control group treated by budesonide (BUD LT). ${ }^{\#} p, \mathrm{OVA}+v s$. NC (Fisher's exact test); ${ }^{*} p$, CRAC LT, BUD LT $v s$. OVA+. The following semiquantitative scale was used to determine degree of infiltration: 0 , tissue did not contain any c-Fos positive cells; 1 , sample contained sporadic or rare c-Fos positive cells; 2 , pulmonary parenchyma with moderate infiltration by c-Fos positive cells; 3 , diffuse or massive infiltration of sample by c-Fos positive cells. 


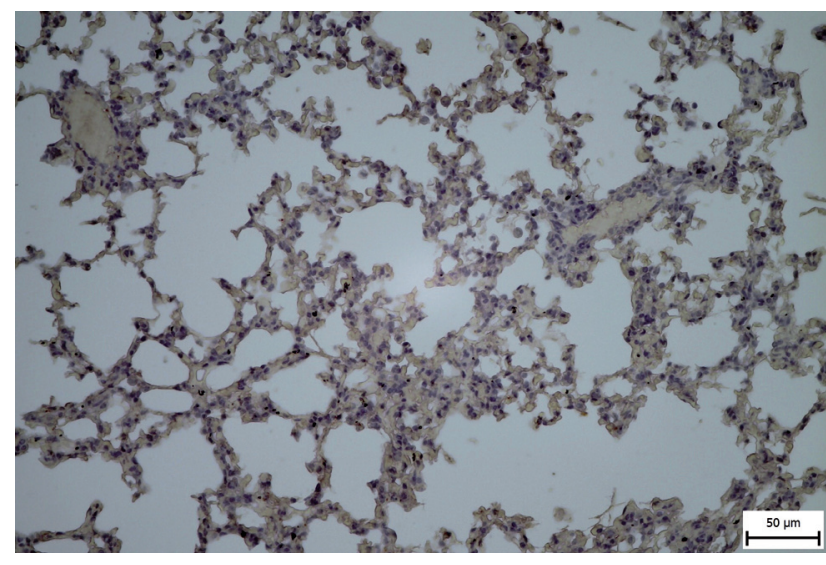

Figure 3. IHC stained airway tissue of the negative unsensitized control group (NC). None c-Fos positivity was detected. Scale bar, $50 \mu \mathrm{m}$.

require sustained $\mathrm{Ca}^{2+}$ influx through CRAC channels and lead to transcription of proinflammatory cytokine genes, including Th2 IL-4, IL-5 and IL-13 as well as TNF- $\alpha$ of mast cells, that cause the typical features of asthma (Feske et al. 2012). Our study confirmed significantly higher plasma levels of IL-4, IL-5 and TNF- $\alpha$ in ovalbumin-sensitized guinea pigs. However, elevation of plasma IL-13 was insignificant. These data correlate to Chen et al. (2009) findings pointed to several differences between human and rodents in development of allergic inflammation that are coupled with the role and plasma levels of IL-13. According to their results rather than a lymphoid cytokine, IL-13 acts more prominently as a molecular bridge linking allergic inflammatory cells to the non-immune cells,

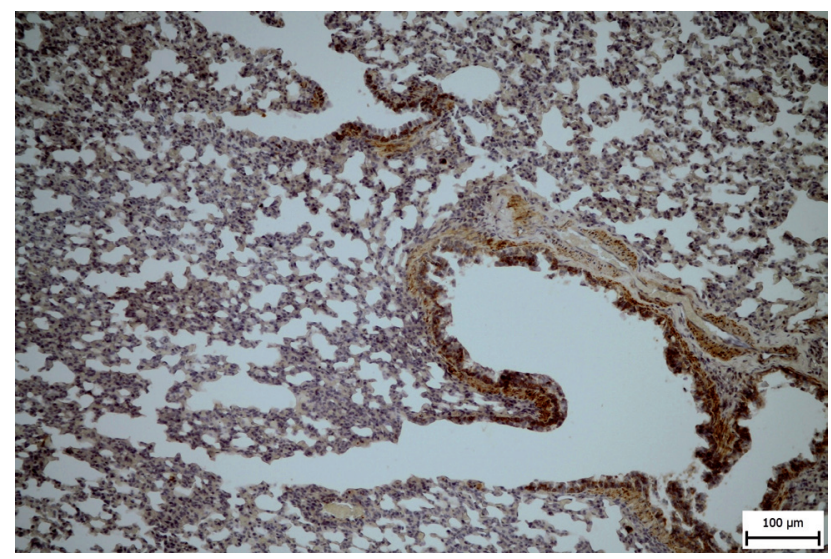

Figure 4. Example of airway tissue obtained from ovalbuminsensitized animals treated with vehicle only $(\mathrm{OVA}+)$ presents grade 3 of epithelial and pulmonary parenchyma c-Fos positivity. Scale bar, $100 \mu \mathrm{m}$.

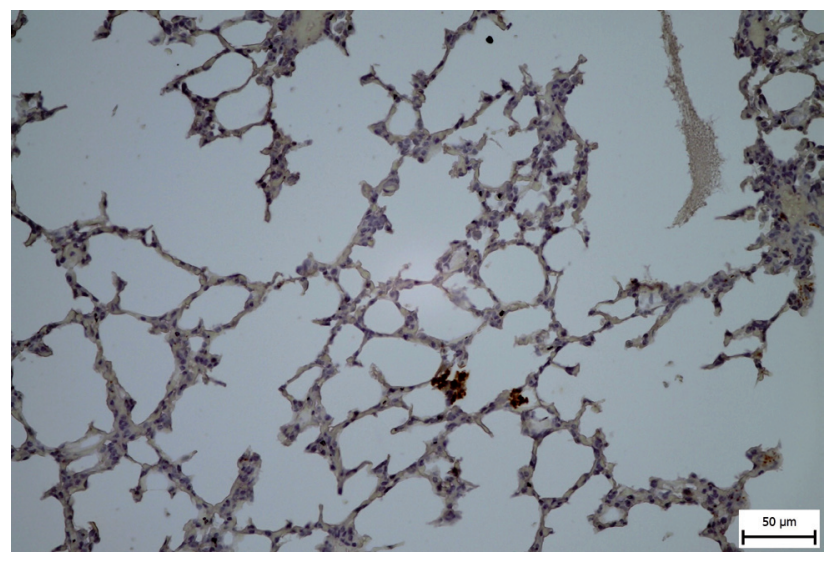

Figure 5. IHC stained tissue of the experimental group (CRAC LT) with focal positivity in pulmonary parenchyma, grade 2 . Scale bar, $50 \mu \mathrm{m}$.

thereby altering physiological function. The results of our experiments also confirmed that blocker of CRAC channels activity suppressed significantly ovalbumine-induced production of IL-4, IL-13 and TNF- $\alpha$ in plasma of guinea pigs experimental model of asthma with comparable efficacy as control antiasthmatic drug, corticosteroid budesonide. However, CRAC channels blocker did not influence IL-5 levels. We assume that it should be associated with low dose of FPCA used for long-term treatment. Similar outstanding study of Yoshino et al. (2007) evaluated the effect of other CRAC channels blocker in doses 1,3 and $10 \mathrm{mg} / \mathrm{kg}$ b.w. and reported significant decrease in plasma IL-5 as the response to administration of 3 and $10 \mathrm{mg} / \mathrm{kg}$ b.w. doses only in rodents.

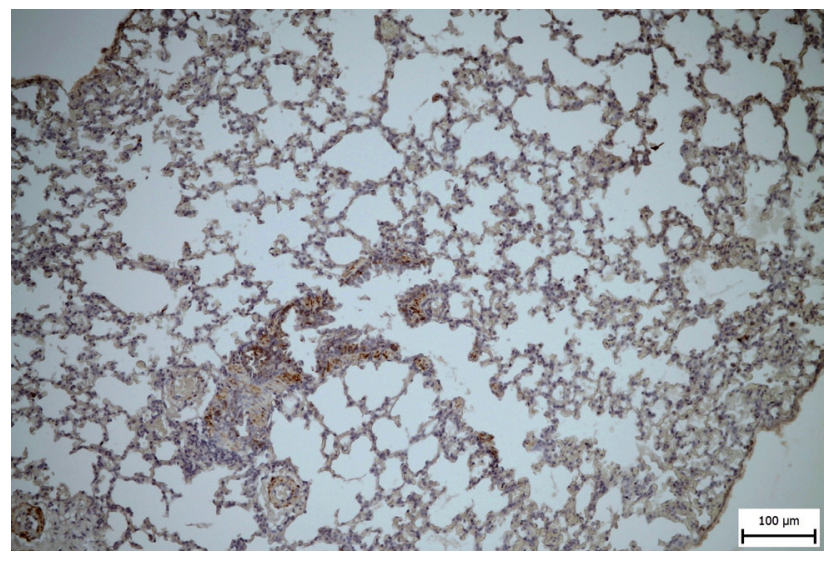

Figure 6. Example of tissue obtained from sensitized animals treated with budesonide (BUD LT) presents grade 3 of epithelial c-Fos positivity and grade 1 of c-Fos positivity localized in the pulmonary parenchyma. Scale bar, $100 \mu \mathrm{m}$. 
Asthma is generally known as an inflammatory condition for which anti-inflammatory glucocorticoids are the standard of care. However, similar efficacy has not been shown for agents targeting inflammatory cells and pathways. This suggests a non-inflammatory cell contribute (e.g., epithelium) to asthmatic inflammation. The data generated in an airway model lacking inflammatory cells, support the concept that asthmatic inflammation is driven by intrinsic inflammatory, fibrogenic, and regenerative characteristics of epithelia (Freishtat et al. 2011). Airway epithelial cells cultured from several species (including human) can generate numerous mediators, including cytokines and chemokines, which can be either bronchoconstrictor, proinflammatory or, in some cases, both (Vareille et al. 2011). Among the cytokines and chemokines produced by airway epithelial cells are several key factors that influence pathologies associated with asthma.

IL-13 plays a central role in airway epithelium physiology and pathophysiology. Its expression increases in response of airway epithelial cells to exposure to diesel exhaust (Pourazar et al. 2004) as well as in response to injury (Allahverdian et al. 2008). IL-13 has been considered as a key mediator of airway remodelling and goblet cell metaplasia in asthma. Several studies have reported that bronchial biopsy specimens and BALF from allergic individuals with asthma show elevated expression of IL-13 compared with control subjects (Humbert et al. 1997; Wu et al. 2010), some levels of relationship between IL-13 and EGFR pathway, in which EGFR activation is necessary for airway remodelling (Shim et al. 2001). Zhu et al. (1999) studies are the first to demonstrate that the chronic overexpression of IL-13 in the lung epithelium generates a phenotype complex that recapitulates many of the features of the Th2 response in human asthma. Glucocorticoids have been shown to strongly repress IL-13 transcription directly within the nucleus and indirectly through mitogen-activated protein kinase (MAPK) pathway in immune and epithelial cells and IL-13 remains elevated in glucocorticoids insensitive asthma (Maneechotesuwan et al. 2009).

IL-13 shares numerous overlapping characteristics with IL-4, where both cytokines promote B cell proliferation, IgE class switching and synthesis in B cells as well as contribute to airway obstruction and remodelling in asthma (Rael and Lockey 2011). Two interesting studies evidenced IL-4 production in airway epithelial cells and its distinct antiapoptotic property. According to Steinke and Borish (2001), increased expression of IL- 4 in the asthmatic airways inhibits apoptosis and might explain the persistence of inflammatory cellular infiltrates. The same authors reported increased levels of IL-4 in asthmatic airways of patients resistant to inhalatory corticosteroids and confirmed that blockage of receptors for IL-4 is a potentially safe and effective new treatment for asthma without use of corticosteroids. Moreover, Hodge et

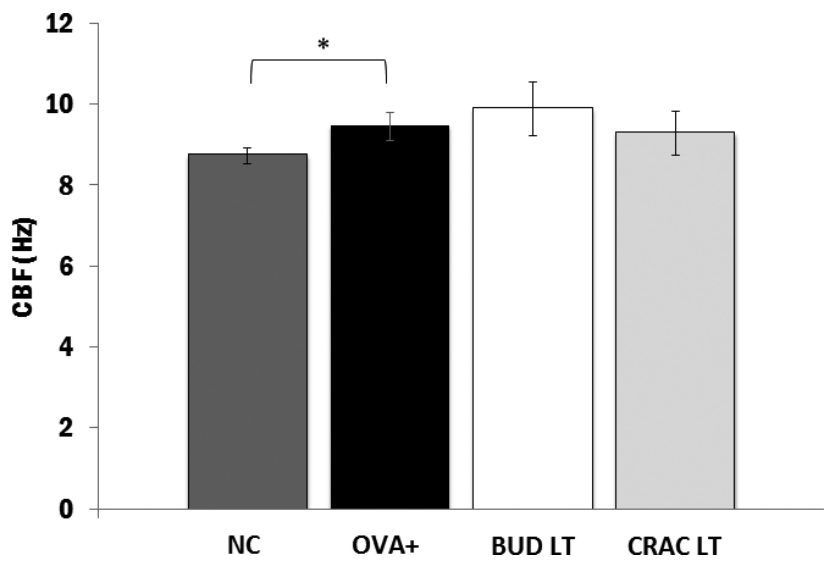

Figure 7. The changes in CBF (ciliary beat frequency) of healthy animals (NC), untreated ovalbumine-sensitized guinea pigs $(\mathrm{OVA}+)$ and sensitized animals treated by budesonide (BUD LT) or CRAC blocker (CRAC LT). ${ }^{*} p<0.05 v s$. OVA+ (t-test).

al. (2002) followed apoptotic human bronchial cells as the important source of IL-4 leading secondary to increased survival of immune cells.

IL-5, generally known as a pleiotropic cytokine that regulates the proliferation, differentiation, and recruitment of eosinophils, is essential for the development of airway eosinophilia during allergic airway inflammation, which is a key feature of allergic airway inflammation in animal models of disease. Increased expression of IL-5 has been reported in BALF from individuals with asthma and correlates with increased asthma severity (Yamada et al. 2000). Wu et al. demonstrated that bronchial epithelial cells are a source of IL-5 in ovalbumin-induced murine model of allergic airway disease and secretion of this cytokine contributes to mucous metaplasia, airway eosinophilia, and allergenspecific IgA levels.

TNF- $\alpha$ is the most widely studied cytokine member of TNF super family. Epithelial cells of airway, T-cells, Blymphocytes, smooth muscle cells, eosinophils and mast cells, produce TNF- $\alpha$ after allergen stimulation. Several lines of evidences indicate that high TNF- $\alpha$ levels are directly linked to asthmatic complications (Mukhopadhyay et al. 2006). In airways epithelial, endothelial and smooth muscle cells of bronchi are the primary targets of TNF- $\alpha$. It causes substantial damage in the bronchial epithelial cells, leakage of epithelial and endothelial cells, hyperplasia of bronchial smooth muscle cells and vasoconstriction (Tillie-Leblond et al. 2002). However, elimination of TNF- $\alpha$ bioactivity alone is not sufficient to abrogate the inflammatory response as it was shown in murine ovalbumin-induced model of allergic inflammation (Rudmann et al. 2000).

Airway epithelial cells produce IL-4, IL-5, IL-13 and TNF- $\alpha$ via the $\mathrm{Ca}^{2+}$-dependent, interconnected NFAT, 
NF- $\kappa \mathrm{B}$ and AP-1 pathways, in which CRAC channels are proposed as a major route of $\mathrm{Ca}^{2+}$ entry (Prakriya 2009). Our experiments showed distinct decrease in levels of IL-4, IL-5, IL-13 and TNF- $\alpha$ in BALF of ovalbumine-sensitized guinea pigs induced by long-term administration of CRAC channels blockers and budesonide. Bronchoalveolar lavage is the most common manner to sample the components of the epithelial lining fluid and determine the protein composition of the pulmonary airways. Furthermore, the effect of CRAC blocker on IL-4 and IL-13 was significantly higher than that of budesonide. These findings correlated with immunohistochemical analysis focused on c-Fos expression, in which CRAC channels blocker suppressed c-Fos positivity of epithelial cells more significantly than budesonide.

In comparison with the broad literature regarding secretory functions of epithelial cells, relatively less reports has focused on changes in cilia movements in asthma. It is generally accepted that the protective beating function of cilia is modulated by different stimuli in asthmatic subjects, e.g. serotonin from activated mast cells or TNF- $\alpha$ caused increase in frequency of cilia beating (Weiterer et al. 2014) and IL-13 induced CBF-inhibitory effect and altered morphology of ciliated cells (Laoukili et al. 2001). Thomas et al. (2010) found decreased CBF, ciliary ultrastructural defects and increases in abnormal ciliary beating patterns in individuals with asthma compared to healthy controls. CBF represents crucial parameter of mucociliary clearance. According to Parekh and Putney (2005), the increase in $\mathrm{CBF}$ is a process mainly dependent on $\mathrm{Ca}^{2+}$ accumulated near plasma membrane in which CRAC channels should be possibly involved. Unlike human studies, we followed significantly increased CBF in ovalbumin-sensitized guinea pigs. However, preliminary results of ongoing study showed high significant decrease in CBF using animal model of airway remodelling (unpublished data). Neither budesonide nor FPCA influenced CBF significantly. In this study we used blocker of CRAC channels inhibiting membrane Orail protein activity. We assume that proliferative and secretory functions of epithelial cells are mainly dependent on upregulated Orail protein in allergic inflammation, as it was followed in airway smooth muscle (Spinelli et al. 2012). It is possible that $\mathrm{Ca}^{2+}$ increasing CBF should be transported into the ciliated cells through alternative ion channels. On the other hand, decrease in CBF associated with airway remodelling participates on airway obstruction. Howbeit our study confirmed that not only budesonide but also CRAC channels blocker did not alter CBF in this experimental allergic asthma model, it will be very important to determine influence of CRAC channels blocker on CBF in model of airway remodelling.

This study determined favourable effect of CRAC channels blocker on airway epithelial cells orchestrating inflammatory responses in asthma. Our findings and results published previously (Sutovska et al. 2013a, 2013b) extend the number of evidences confirming these channels as very promising target for the new antiasthmatic strategy.

Acknowledgements. The authors acknowledge Katarina Jesenska for her outstanding technical assistance during experimental works. This study was supported by the projects "Centre of Experimental and Clinical Respirology I", "Centre of Experimental and Clinical Respirology II", "BioMed" co-financed from EC sources and by the grants VEGA No. 1/0020/11, 1/0127/13, 1/0165/14, MZ No. 2012/35-UKMA-12 and APVV No. 0305-12.

Conflicts of Interest Statement. The authors declare none conflicts of interest in relation to this article.

\section{References}

Adcock J. M., Caramori G. (2001): Cross-talk between pro-inflammatory transcription factors and glucocorticoids. Immunol. Cell Biol. 79, 376-384 http://dx.doi.org/10.1046/j.1440-1711.2001.01025.x

Allahverdian S., Harada N., Singhera G. K., Knight D. A., Dorscheid D. R. (2008): Secretion of IL-13 by airway epithelial cells enhances epithelial repair via HB-EGF. Am. J. Respir. Cell Mol. Biol. 38, 153-160 http://dx.doi.org/10.1165/rcmb.2007-0173OC

Braiman A., Priel Z. (2001): Intracellular stores maintain stable cytosolic $\mathrm{Ca} 2+$ gradients in epithelial cells by active $\mathrm{Ca} 2+$ redistribution. Cell Calcium 30, 361-371 http://dx.doi.org/10.1054/ceca.2001.0245

Chen W., Sivaprasad U., Tabata Y., Gibson A. M., Stier M. T., Finkelman F. D., Hershey G. K. (2009): IL-13R alpha 2 membrane and soluble isoforms differ in humans and mice. J. Immunol. 183, 7870-7876 http://dx.doi.org/10.4049/jimmunol.0901028

Dave V., Childs T., Whitsett J. A. (2004): Nuclear factor of activated $\mathrm{T}$ cells regulates transcription of the surfactant protein $\mathrm{D}$ gene (Sftpd) via direct interaction with thyroid transcription factor-1 in lung epithelial cells. J. Biol. Chem. 279, 34578-34588 http://dx.doi.org/10.1074/jbc.M404296200

Feske S. (2010): CRAC channelopathies. Pflügers Arch. 460, $417-435$ http://dx.doi.org/10.1007/s00424-009-0777-5

Feske S., Skolnik E. Y., Prakriya M. (2012): Ion channels and transporters in lymphocyte function and imunity. Nat. Rev. Immunol. 12, 532-547 http://dx.doi.org/10.1038/nri3233

Franova S., Joskova M., Sadlonova V., Pavelcikova D., Mesarosova L., Novakova E., Sutovska M. (2013): Experimental model of allergic asthma. Adv. Exp. Med. Biol. 756, 49-55 http://dx.doi.org/10.1007/978-94-007-4549-0_7

Freishtat R. J., Watson A. M., Benton A. S., Iqbal S. F., Pillai D. K., Rose M. C., Hoffman E. P. (2011): Asthmatic airway epithelium is intrinsically inflammatory and mitotically dyssynchronous. Am. J. Respir. Cell Mol. Biol. 44, 863-869 http://dx.doi.org/10.1165/rcmb.2010-0029OC 
Fujioka S., Niu J., Schmidt Ch., Sclabas G. M., Peng B., Uwagawa T., Li Z., Evans D. B., Abbruzzese J. L., Chiao P. J. (2004): NF-кB and AP-1 connection: mechanism of NF- $\kappa B$-dependent regulation of AP-1 activity. Mol. Cell. Biol. 24, 7806-7819 http://dx.doi.org/10.1128/MCB.24.17.7806-7819.2004

Gwack Y., Srikanth S., Oh-Hora M., Hogan P. G., Lamperti E. D., Yamashita M., Gelinas C., Neems D. S., Sasaki Y., Feske S., Prakriya M., Rajewsky K., Rao A. (2008): Hair loss and defective T- and B-cell function in mice lacking ORAI1. Mol. Cell. Biol. 28, 5209-5222 http://dx.doi.org/10.1128/MCB.00360-08

Hargas L., Koniar D., Stofan S. (2011): Sophisticated biomedical tissue measurement using image analysis and virtual instrumentation. In: Practical Applications and Solutions Using LabVIEW $^{\text {sx }}$ Software. (Ed. S. Folea). InTech http://dx.doi.org/10.5772/21823

Hodge S., Hodge G., Flower R., Reynolds P. N., Scicchitano R., Holmes M. (2002): Up-regulation of production of TGF- $\beta$ and IL- 4 and down-regulation of IL- 6 by apoptotic human bronchial epithelial cells. Immunol. Cell Biol. 80, $537-543$ http://dx.doi.org/10.1046/j.1440-1711.2002.01120.x

Humbert M., Durham S. R., Kimmitt P., Powell N., Assoufi B., Pfister R., Menz G., Kay A. B., Corrigan C. J. (1997): Elevated expression of messenger ribonucleic acid encoding IL-13 in the bronchial mucosa of atopic and nonatopic subjects with asthma. J. Allergy Clin. Immunol. 99, 657-665 http://dx.doi.org/10.1016/S0091-6749(97)70028-9

Laoukili J., Perret E., Willems T., Minty A., Parthoens E., Houcine O., Coste A., Jorissen M., Marano F., Caput D., Tournier F. (2001): IL-13 alters mucociliary differentiation and ciliary beating of human respiratory epithelial cells. J. Clin. Invest. 108, 1817-1824 http://dx.doi.org/10.1172/JCI200113557

Lemanske R. F. Jr., Busse W.W. (2010): Asthma: clinical expression and molecular mechanisms. J. Allergy Clin. Immunol. 125 (Suppl. 2), S95-102 http://dx.doi.org/10.1016/j.jaci.2009.10.047

Macián F., López-Rodrígez C., Rao A. (2001): Partners in transcription: NFAT and AP-1. Oncogene 20, 2476 - 2489 http://dx.doi.org/10.1038/sj.onc.1204386

Maneechotesuwan K., Yao X., Ito K., Jazrawi E., Usmani O. S., Adcock I. M., Barnes P. J. (2009): Suppression of GATA-3 nuclear import and phosphorylation: a novel mechanism of corticosteroid action in allergic disease. PLoS Med. 6, 1-12 http://dx.doi.org/10.1371/journal.pmed.1000076

McNally B. A., Somasundaram A., Yamashita M., Prakriya M. (2012): Gated regulation of CRAC channel ion selectivity by STIM1. Nature 482, 241-245

Mukhopadhyay S., Hoidal J. R., Mukherjee T. K. (2006): Role of TNF- $\alpha$ in pulmonary pathophysiology. Respir. Res. 7, 125 http://dx.doi.org/10.1186/1465-9921-7-125

Page K., Li J., Zhou L., Iasvovskaia S., Corbit K. C., Soh J. W., Weinstein I. B, Brasier A. R., Lin A., Hershenson M. B. (2003): Regulation of airway epithelial cell NF-kappa B-dependent gene expression by protein kinase $\mathrm{C}$ delta. J. Immunol. 170, 5681-5689

http://dx.doi.org/10.4049/jimmunol.170.11.5681
Parekh A. B., Putney J. W. Jr. (2005): Store-operated calcium channels. Physiol. Rev. 85, 757-810 http://dx.doi.org/10.1152/physrev.00057.2003

Parekh A. B. (2010): Store-operated CRAC channels: function in health and disease. Nat. Rev. Drug Discov. 9, 399-410 http://dx.doi.org/10.1038/nrd3136

Pourazar J., Frew A. J., Blomberg A., Helleday R., Kelly F. J., Wilson S., Sandström T. (2004): Diesel exhaust exposure enhances the expression of IL-13 in the bronchial epithelium of healthy subjects. Respir. Med. 98, 821-825 http://dx.doi.org/10.1016/j.rmed.2004.02.025

Prakriya M. (2009): The molecular physiology of CRAC channels. Immunol. Rev. 231, 88-98 http://dx.doi.org/10.1111/j.1600-065X.2009.00820.x

Rael E. L., Lockey R. F. (2011): Interleukin-13 signaling and its role in asthma. World Allergy Organ J. 4, 54-64 http://dx.doi.org/10.1097/WOX.0b013e31821188e0

Rudmann D. G., Moore M. W., Tepper J. S., Aldrich M. C., Pfeiffer J. W., Hogenesch H., Tumas D. B. (2000): Modulation of allergic inflammation in mice deficient in TNF receptors. Am. J. Physiol. Lung Cell. Mol. Physiol. 279, L1047-1057

Shim J. J., Dabbagh K., Ueki I. F., Dao-Pick T., Burgel P. R., Takeyama K., Tam D. C., Nadel J. A. (2001): IL-13 induces mucin production by stimulating epidermal growth factor receptors and by activating neutrophils. Am. J. Physiol. Lung Cell Mol. Physiol. 280, L134-140

Spinelli A. M., González-Cobos J. C., Motiani R. K., Rowan S., Zhang W., Garrett J., Vincent P. A., Matrougui K., Singer H. A., Trebak M. (2012): Airway smooth muscle STIM1 and Orai1 are upregulated in asthmatic mice and mediate PDGF-activated SOCE, CRAC currents, proliferation, and migration. Pflügers Arch. 464, 481-492 http://dx.doi.org/10.1007/s00424-012-1160-5

Steinke J. W., Borish L. (2001): Th2 cytokines and asthma. Interleukin-4: its role in the pathogenesis of asthma, and targeting it for asthma treatment with interleukin- 4 receptor antagonists. Respir. Res. 2, 66-70 http://dx.doi.org/10.1186/rr40

Sutovska M., Adamkov M., Kocmalova M., Mesarosova L., Oravec M., Franova S. (2013a): CRAC ion channels and airway defense reflexes in experimental allergic inflammation. Adv. Exp. Med. Biol. 756, 39-48 http://dx.doi.org/10.1007/978-94-007-4549-0_6

Sutovska M., Kocmalova M., Adamkov M., Vybohova D., Mikolka P., Mokra D., Hatok J., Antosova M., Franova S. (2013b): The longterm administration of Orai 1 antagonist possesses antitussive, bronchodilatory and anti-inflammatory effects in experimental asthma model. Gen. Physiol. Biophys. 32, 251-259 http://dx.doi.org/10.4149/gpb_2013018

Teff Z., Priel Z., Gheber L. A. (2008): The forces applied by cilia depend linearly on their frequency due to constant geometry of the effective stroke. Biophys. J. 94, 298-305 http://dx.doi.org/10.1529/biophysj.107.111724

Thomas B., Rutman A., Hirst R. A., Haldar P., Wardlaw A. J., Bankart J., Brightling C. E., O`Callaghan C. (2010): Ciliary dysfunction and ultrastructural abnormalities are features of severe asthma. J. Allergy Clin. Immunol. 126, 722-729 http://dx.doi.org/10.1016/j.jaci.2010.05.046 
Tillie-Leblond I., Guery B. P., Janin A., Leberre R., Just N., Pittet J. F., Tonnel A. B., Gosset P. (2002): Chronic bronchial allergic inflammation increases alveolar liquid clearance by TNF-alphadependent mechanism. Am. J. Physiol. Lung Cell Mol. Physiol. 283, L1303-1309

Vareille M., Kieninger E., Edwards M. R., Regamey N. (2011): The airway epithelium: soldier in the fight against respiratory viruses. Clin. Microbiol. Rev. 24, 210-229 http://dx.doi.org/10.1128/CMR.00014-10

Weiterer S., Schulte D., Müller S., Kohlen T., Uhle F., Weigand M. A., Henrich M. (2014): Tumor necrosis factor alpha induces a serotonin dependent early increase in ciliary beat frequency and epithelial transport velocity in murine tracheae. PLoS One 9, e91705 http://dx.doi.org/10.1371/journal.pone.0091705

Wu C. A., Peluso J. J., Zhu L., Lingenheld E. G., Walker S. T., Puddington L. (2010): Bronchial epithelial cells produce IL-5: Implications for local immune responses in the airways. Cell. Immunol. 264, 32-41 http://dx.doi.org/10.1016/j.cellimm.2010.04.008

Yamada H., Yamaguchi M., Yamamoto K., Nakajima T., Hirai K., Morita Y., Sano Y., Yamada H. (2000): Eotaxin in induced sputum of asthmatics: relationship with eosinophils and eosinophil cationic protein in sputum. Allergy 55, 392-397 http://dx.doi.org/10.1034/j.1398-9995.2000.00474.x

Yoshino T., Ishikawa J., Ohga K., Morokata T., Takezawa R., Morio H., Okada Y., Honda K., Yamada T. (2007): YM-58483, a selective CRAC channel inhibitor, prevents antigen-induced airway eosinophilia and late phase asthmatic responses via Th2 cytokine inhibition in animal models. Eur. J. Pharmacol. 560, 225-233 http://dx.doi.org/10.1016/j.ejphar.2007.01.012

Zagoory O., Braiman A., Priel Z. (2002): The mechanism of ciliary stimulation by acetylcholine. J. Gen. Physiol. 119, 329-339 http://dx.doi.org/10.1085/jgp.20028519

Zhu Z., Homer R. J., Wang Z., Chen Q., Geba G. P., Wang J., Zhang Y., Elias J. A. (1999): Pulmonary expression of interleukin-13 causes inflammation, mucus hypersecretion, subepithelial fibrosis, physiologic abnormalities, and eotaxin production. J. Clin. Invest. 103, 779-788 http://dx.doi.org/10.1172/JCI5909

Received: August 4, 2014

Final version accepted: September 29, 2014

First published online: March 2, 2015 